\title{
Part-instance association in the categorization of acts
}

\author{
IVEN VAN MECHELEN and PAUL DE BOECK \\ University of Leuven, Leuven, Belgium
}

\begin{abstract}
Rips and Conrad (1989) found a kind-part reciprocal effect in models of the mind, in that one mental activity is part of another if the second is a kind of the first, and vice versa. In the present paper, we hypothesize that a formally analogous effect occurs at the level of activity instances. In particular, we hypothesize that an act is judged to be an instance of an act category referred to by an activity verb if the activity is judged to be an important part of the act, and vice versa. Empirical support for this hypothesis is found in three studies with activity verbs. The converse part-instance relation is further noted to parallel the part-instance association for a specific type of metonymically defined categories. Rips and Conrad's kind-part reciprocal effect is shown to be a logical consequence of the converse part-instance relation.
\end{abstract}

In a study on models of the mind, Rips and Conrad (1989) found a remarkable kind-part reciprocal effect, in that if one mental activity is judged to be a kind of another, then the second is judged to be part of the first, and vice versa. For example, most people agree that analyzing is a kind of thinking and that thinking is part of analyzing. This reciprocal effect is puzzling. In general, it does not hold for objects: For example, a nose is said to be part of a face, but a face is not a kind of nose; a poodle is a kind of dog, but dog is not part of a poodle.

In this paper, we hypothesize that in models of activities a converse relation, which is formally analogous to Rips and Conrad's (1989) kind-part reciprocal effect, occurs at the level of activity instances. After explicating this hypothesis, we will present three studies with empirical evidence for it. Finally, we make a link with metonymical reasoning, and we argue that the kind-part reciprocal effect is a logical consequence of the converse relation at the instance level.

\section{Structural Organization of Acts}

The basic building block of any model of activities is the single, specific action performed by a certain person at a certain moment in a certain situation. For such specific actions, we reserve the term acts. Acts usually cannot be characterized by means of a single expression. Like most specific objects that do not have a proper name, they are referred to by giving a rather extensive description. For example, suppose that John has two ways to drive home from the department, with traffic jams sometimes

\footnotetext{
We thank Lance Rips, Dirk Geeraerts, Seymour Rosenberg, Machteld Hoskens, Rianne Janssen, and two anonymous reviewers for their helpful comments on a previous draft of this article. Correspondence should be addressed to I. Van Mechelen, Department of Psychology, University of Leuven, Tiensestraat 102, B-3000 Leuven, Belgium (e-mail: iven@blekul11.bitnet).
}

occurring on one and sometimes on the other. One may consider the mental act of John, who, on his way home at 5 p.m., after a moment of doubt chooses whether he will turn left or right at the next crossing.

Models of activities provide a structural organization for these acts. Two types of structural relations are considered here: those between acts and act categories, and those between acts and act components.

First, acts can be grouped in act categories. These categories are labeled as verbs, such as thinking, reasoning, and walking. Acts are called their instances. For example, the above-mentioned act of John could be called an instance of the act category "deciding." A single act may be an instance of several act categories, the number of applicable categories probably depending on the complexity of the act in question.

Second, one may distinguish components or parts of acts. These parts, too, are labeled as verbs (e.g., thinking, walking, etc.). For example, "analyzing"' could be said to be part of John's act as mentioned above. Although the part-whole relationship between acts and their components seems similar to the part-whole relationship within the domain of physical objects, the two relationships are not identical. One reason for this is that acts are extended in time rather than in space. Moreover, usually they are only poorly structured, blurred wholes (Cruse, 1986, p. 174).

One remarkable thing about models for activities is that the same type of verb is used to label both act categories and act parts. Moreover, it is intuitively plausible that for many acts the very same verb can designate both a category for that act and a part of it. So, in the example of John's act, one could say that it is an instance of deciding and that deciding is part of it. This suggests that in this domain there could be a close association between instance-of and part-of relations. In this article, we hypothesize that if an activity is judged to be a part of an act, then the act will be judged to be an instance of that 
activity. Conversely, if an act is judged to be an instance of an activity, then we hypothesize that the activity will be judged to be a part of that act. Stated in other words, we hypothesize that a converse part-instance relation holds in models of activities, which accounts for the fact that an act is judged to be an instance of an act category as referred to with an activity verb if the activity is judged to be a part of that act, and vice versa.

To be sure, it is not too difficult to find exceptions to the converse relation predicted above. For example, although subjects probably will agree that analyzing is part of John's act, it is less obvious that they will agree that this act is also an instance of analyzing. We conjecture that this has to do with the relatively low importance of analyzing as a part of the act in question. We therefore examined whether the converse relation occurs more often for important parts than for less important parts. If an act is judged to be an instance of an act category referred to by an activity verb, will the activity then be judged to be an important part of that act, and vice versa?

Note that the hypothesized converse part-instance relation, which formally resembles the kind-part reciprocal effect found by Rips and Conrad (1989), clearly differs from the latter effect. The kind-part reciprocal effect is an effect at the level of category-category relations, whereas the hypothesized converse part-instance relation is situated at the level of the category ascription of specific instances (i.e., acts). Otherwise, the distinction between instance-of and kind-of relations has deep philosophical roots (see, e.g., Frege, 1897/1964). In settheoretical terms, the distinction is that between the relations "is an element of" and "is a subset of."

\section{STUDY 1}

In our first study, we tested the hypothesized converse relation for mental activities. We collected judgments about the extent to which some given mental activities are an important part of mental acts and about the extent to which these acts are a good instance of the same mental activities. Our prediction was that the more a mental activity would be judged to be a part of a mental act, the more that act would be called an instance of the activity. We further expected that the converse association between being an important part and being an instance would be even stronger than that between being a part and being an instance.

\section{Method}

Selection of instances. For our study, a list of mental acts was needed. Therefore, three activities (choosing, analyzing, and interpreting) were selected from Rips and Conrad's (1989) list of mental activity verbs, and a group of 5 subjects was asked to list, for each activity, "five very concrete, mental acts of a certain person at a certain moment that were an instance of that activity." All subjects were psychology students at the University of Leuven who were not involved in cognitive research. This procedure yielded 25 instances of each category. We randomly selected 15 instances from each category. The resulting 45 acts, put in a uniform syn- tactic form, constituted the stimulus set for Study 1. The following are examples of acts: "You decide to type your text in typeface A rather than in typeface B" "; "I look for the themes occurring in a text"; "The old woman thinks that the long hair of her grandson is very asocial." (For an English translation of the complete, originally Dutch list of acts, see Appendix A).

Part/instance judgments. Two new groups (8 subjects in each) were asked to judge the 45 acts. The subjects again were psychology students at the University of Leuven. They were presented the acts in random order. Two randomizations of the acts were prepared-one for the first group and the other for the second group. The subjects in the first group were asked, for each combination of a mental activity verb with an act, whether the activity was part of the act and, if so, to what extent it was an important part. For this rating, they used a single 5 -point rating scale $(1=$ not a part, $2=a$ rather less important part, $3=$ an important part, $4=a$ very important part, $5=$ an extremely important part). The anchor labels of this scale were chosen such that 2 could be considered as the cutoff value for parts and 3 could be considered as the cutoff value for important parts. In an analogous way, subjects in the second group had to indicate on a 5-point scale, for each combination of a mental activity verb with an act, whether the act was an instance of the activity and, if so, to what extent it was a good instance $(1=$ not an instance, $2=a$ rather less good instance, $3=a$ good instance, $4=a$ very good instance, $5=$ an extremely good instance). On this scale, 2 could be considered to be the cutoff value for instances.

\section{Results}

Part-of and instance-of judgments appeared to be reliable: for the part-of judgments, the intraclass correlation coefficients ICC $(2,8)$ (Shrout \& Fleiss, 1979) were .94, .91 , and .92, and for the instance-of judgments, they were $.94, .94$, and .90 (for choosing, analyzing, and interpreting, respectively).

The instance-of and part-of ratings for each of the three verbs then were averaged across judges, and correlations between the average ratings were computed (across all 45 acts); these correlations are given in Table 1. It appears that, for each verb, the average part-of rating for an act was strongly associated with its average instanceof rating, the correlations being about as high as the reliability of the respective ratings. This strongly supports our hypothesis. All correlations between instance-of and part-of ratings for different verbs were negative, which points to the fact that the part-instance association was highly specific for each verb.

To compare the strength of the important part-instance and the part-instance associations, first the raw part-of ratings were dichotomized by determining, for each combination of a mental activity verb with an act, whether a majority of the raters agreed that the activity was an important part of the act (i.e., whether a majority of the raters gave a rating value of 3 or more). Similarly, the instance-of ratings were dichotomized by determining, for each combination of a mental activity verb with an act, whether a majority of the raters agreed that the act was an instance of the activity (rating value of 2 or more). The upper part of Table 2 shows for each important part-instance cross-classification the $\chi^{2}$ value and the value of $\phi$. It appears that, for each of the three verbs, 
Table 1

Correlations Between Instance-of and Part-of Ratings

for Three Mental Activity Verbs (Study 1)

\begin{tabular}{|c|c|c|c|c|c|c|}
\hline & \multicolumn{3}{|c|}{ Instance of: } & \multicolumn{3}{|c|}{ Part of: } \\
\hline & Choosing & Analyzing & Interpreting & Choosing & Analyzing & Interpreting \\
\hline \multicolumn{7}{|l|}{ Instance of: } \\
\hline $\begin{array}{l}\text { Choosing } \\
\text { Analyzing } \\
\text { Interpreting }\end{array}$ & & -.40 & $\begin{array}{l}-.62 \\
-.26\end{array}$ & $\begin{array}{r}.96 \\
-.32 \\
-.63\end{array}$ & $\begin{array}{r}-.36 \\
.93 \\
-.27\end{array}$ & $\begin{array}{r}-.72 \\
-.12 \\
.90\end{array}$ \\
\hline \multicolumn{7}{|l|}{ Part of: } \\
\hline $\begin{array}{l}\text { Choosing } \\
\text { Analyzing } \\
\text { Interpreting }\end{array}$ & & & & & -.32 & $\begin{array}{l}-.73 \\
-.11\end{array}$ \\
\hline
\end{tabular}

the $\chi^{2}$ value was significant and that $\phi$ was high. To compute the analogous associations with simple part-of ratings, the instance-of ratings were dichotomized as above; whereas, for the part-of ratings, we determined, for each combination of a mental activity verb with an act, whether a majority of the raters agreed that the activity was part of the act (rating value of 2 or more). The lower part of Table 2 shows the results of the analyses for the resulting part-instance $(2 \times 2)$ cross-classifications of the acts. Again, for each of the three verbs, the $\chi^{2}$ value was significant. Furthermore, in line with our prediction, the $\phi$ values, which now varied from moderately high to high, were less than or about equal to the corresponding values for the important part-instance cross-classifications.

\section{STUDIES 2 AND 3}

In Study 1, the predicted converse part-instance relation was consistently found for three mental activity verbs sampled from Rips and Conrad's (1989) list of analytic (i.e., cognitive) activity terms. In Study 2, we explored the robustness of our findings with three new mental activity verbs sampled from Rips and Conrad's list of nonanalytic mental activity terms. In Study 3, we further examined whether our findings generalize to nonmental (i.e., physical) activity verbs.

\section{Method}

The methods of Studies 2 and 3 were similar to those of Study 1. Twenty-one new subjects participated in Study 2, and another 21 new subjects participated in Study 3 . In each study, 5 subjects generated mental acts, 8 made part-of judgments, and 8 made

Table 2

Associations Between Dichotomized Part-of and Instance-of Ratings for Three Mental Activity Verbs (Study 1)

\begin{tabular}{crrr} 
& \multicolumn{4}{c}{ Choosing } & Analyzing & Interpreting \\
\hline \multicolumn{4}{c}{ Important Part-Instance } \\
$\chi^{2}$ & $28.1^{*}$ & $18.6^{*}$ & $27.3^{*}$ \\
$\phi$ & .79 & .64 & .78 \\
& & Part-Instance & \\
$\chi^{2}$ & $28.8^{*}$ & $4.4 \dagger$ & $14.3^{*}$ \\
$\phi$ & .80 & .31 & .56 \\
\hline${ }^{*} p<.001$. & $\dagger p<.05$ & &
\end{tabular}

instance-of judgments. All subjects were psychology students at the University of Leuven. The nonanalytic mental activity verbs feeling, realizing, and imaging were used for Study 2 , and the physical activity verbs pushing, throwing, and turning were used for Study 3. English translations of the original Dutch lists of the acts that were used in Studies 2 and 3 are presented in Appendixes B and $\mathrm{C}$.

\section{Results}

Part-of and instance-of judgments again appeared to be reliable: for the nonanalytic terms, the intraclass correlation coefficients $\operatorname{ICC}(2,8)$ were $.89, .91$, and .96 , and $.89, .90$, and .92 , respectively; for the physical terms, they were $.95, .98$, and .96 , and $.92, .98$, and .96 , respectively.

The correlations between the averaged instance-of and part-of judgments are given in Tables 3 and 4 for Studies 2 and 3 , respectively. Instance-of and part-of ratings appear to be very strongly associated for both the nonanalytic mental activities and the physical activities. All correlations were higher than .92. Furthermore, all correlations between instance-of and part-of ratings again were negative, which indicates the specificity of the partinstance association for each verb.

The results of the importance analyses for the nonanalytic mental activity verbs are presented in Table 5 . All $\chi^{2}$ values were significant, and the corresponding $\phi$ values were moderately high. All important part-instance $\phi$ values exceeded their part-instance counterparts.

From the importance analyses of the physical activity verbs (see Table 6), it appears that all $\chi^{2}$ values again were significant. All corresponding $\phi$ values were very high. The importance effect, however, did not show up here, and, for two verbs, the part-instance $\phi$ even exceeded its important part-instance counterpart.

\section{DISCUSSION}

In three studies, the predicted converse part-instance relation was consistently found. Hence, we can conclude that the relation is a robust phenomenon that holds for both mental (analytic as well as nonanalytic) and physical activities. A similar relation, however, does not seem to hold for objects. For example, for a specific sitting unit that is called an instance of a chair, one will generally 
Table 3

Correlations Between Instance-of and Part-of Ratings

for Three Nonanalytic Mental Activity Verbs (Study 2)

\begin{tabular}{|c|c|c|c|c|c|c|}
\hline & \multicolumn{3}{|c|}{ Instance of: } & \multicolumn{3}{|c|}{ Part of: } \\
\hline & Feeling & Realizing & Imaging & Feeling & Realizing & Imaging \\
\hline \multicolumn{7}{|l|}{ Instance of: } \\
\hline $\begin{array}{l}\text { Feeling } \\
\text { Realizing } \\
\text { Imaging }\end{array}$ & & .14 & $\begin{array}{l}-.44 \\
-.83\end{array}$ & $\begin{array}{r}.92 \\
-.02 \\
-.27\end{array}$ & $\begin{array}{r}.08 \\
.96 \\
-.81\end{array}$ & $\begin{array}{r}-.51 \\
-.83 \\
.97\end{array}$ \\
\hline \multicolumn{7}{|l|}{ Part of: } \\
\hline $\begin{array}{l}\text { Feeling } \\
\text { Realizing } \\
\text { Imaging }\end{array}$ & & & & & -.06 & $\begin{array}{l}-.35 \\
-.81\end{array}$ \\
\hline
\end{tabular}

not say that a chair is part of it; similarly, whereas a nose is a part of any specific face, a specific face will not be called an instance of a nose.

In a more fine-grained analysis, for (analytic as well as nonanalytic) mental activity verbs, the converse partinstance association appears to be even stronger for important parts. The latter was not the case for physical activity verbs; however, for these verbs, all important part-instance associations were also strong. Within the domain of mental activities, several factors could contribute to part importance, such as perceptual salience and functional significance (Tversky \& Hemenway, 1984).

It may be of further interest to discuss briefly the connection between our converse part-instance results and two related phenomena. Successively, we address the connection with metonymically defined categories and with the kind-part reciprocal effect found by Rips and Con$\mathrm{rad}(1989)$.

\section{Metonymical Categorization}

It is interesting to note that the converse part-instance relation is formally identical with the part-instance relation for a specific kind of metonymically defined category. To develop this argument, we will first briefly go through the basic principles of metonymical reasoning.

In general, a metonymy consists of using the name of one element for that of another of which it is an attribute or with which it is associated. For example, the term White House may be metonymically used to designate its inhabitant, the President of the United States. Originally, metony- mies were considered to be figures of speech or rhetorical devices. However, Lakoff and Johnson (1980) made a strong argument for the case that the human conceptual system is fundamentally metaphorical and metonymical in nature. They further considered the basic impetus for the use of metonymic models to be cognitive efficiency. In particular, in metonymic models, the Target Concept $A$ is replaced by an Associated Concept B, because B is easier to understand, to remember, or to recognize, or because it is more immediately useful (Lakoff, 1987).

The specific subtype of metonymies that is of interest here is the one that traditional rhetoricians have called pars pro toto or synecdoche. In this type of metonymy, the name of an important part is used to designate the whole of which it is a constituent. For example, strings may be used to designate chords as well as stringed instruments. For our purposes, the important point is that for pars pro toto cases the converse part-instance relation also holds. For example, each specific instrument with strings as an important part is an instance of the category strings, and vice versa.

It would be interesting to go beyond a formal similarity and to explore in further research the possibility that the converse part-instance relation in the categorization of acts has a metonymical basis. It seems plausible to suppose that the poorly structured nature of many acts brings about a pressure toward cognitive efficiency. This pressure could result in a categorization of the acts on the basis of their (important) parts, the categories being metonymically named with the labels of their parts.

Table 4

Correlations Between Instance-of and Part-of Ratings for Three Physical Activity Verbs (Study 3)

\begin{tabular}{|c|c|c|c|c|c|c|}
\hline & \multicolumn{3}{|c|}{ Instance of: } & \multicolumn{3}{|c|}{ Part of: } \\
\hline & Pushing & Throwing & Turning & Pushing & Throwing & Turning \\
\hline \multicolumn{7}{|l|}{ Instance of: } \\
\hline $\begin{array}{l}\text { Pushing } \\
\text { Throwing } \\
\text { Turning }\end{array}$ & & -.32 & $\begin{array}{l}-.60 \\
-.36\end{array}$ & $\begin{array}{r}.96 \\
-.41 \\
-.56\end{array}$ & $\begin{array}{r}-.32 \\
.97 \\
-.43\end{array}$ & $\begin{array}{r}-.54 \\
-.40 \\
.97\end{array}$ \\
\hline \multicolumn{7}{|l|}{ Part of: } \\
\hline $\begin{array}{l}\text { Pushing } \\
\text { Throwing } \\
\text { Turning }\end{array}$ & & & & & -.38 & $\begin{array}{l}-.52 \\
-.47\end{array}$ \\
\hline
\end{tabular}


Table 5

Associations Between Dichotomized Part-of and Instance-of Ratings for Three Nonanalytic Mental Activity Verbs (Study 2)

\begin{tabular}{cccc} 
& Feeling & Realizing & . Imaging \\
\hline \multicolumn{4}{c}{ Important } \\
\hline$\chi^{2}$ & 17.5 & 15.7 & 13.5 \\
$\phi$ & .62 & .59 & .55 \\
& & Part-Instance & \\
$\chi^{2}$ & 10.9 & 14.7 & 12.8 \\
$\phi$ & .49 & .57 & .53 \\
\hline
\end{tabular}

Note-For all $\chi^{2}$ values, $p<.001$.

Table 6

Associations Between Dichotomized Part-of and Instance-of Ratings for Three Physical Activity Verbs (Study 3)

\begin{tabular}{cccc} 
& Pushing & Throwing & Turning \\
\cline { 2 - 4 }$\chi^{2}$ & 31.0 & \multicolumn{1}{c}{ Important Part-Instance } \\
$\phi$ & .83 & .90 & 13.7 \\
& & Part-Instance & .95 \\
$\chi^{2}$ & 37.3 & 45.0 & 37.6 \\
$\phi$ & .91 & 1.0 & .91 \\
\hline
\end{tabular}

Note-For all $\chi^{2}$ values, $p<.001$.

Note that a classification on the basis of parts is not remarkable as such. Such a classification may also occur for objects, examples being the categories two-wheelers, hoofed animals, and broadleaf trees. What is rather uncommon is the use of the same word to denote both part and whole.

Note also that if indeed the converse part-instance relation would have a metonymical basis, this would imply that activity verbs are polysemous (or at least semantically ambiguous), such that if an act is an instance of an activity denoted by a verb in meaning ${ }_{1}$, this implies that the act under study has a part denoted by the same verb

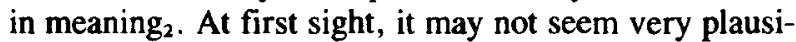
ble that this is indeed the case. Yet, at least for a number of activity verbs, it is possible to pin down some kind of semantic vagueness. For example, a process of listing alternatives, estimating and comparing advantages/disadvantages, and then choosing can be called an instance of deciding. Deciding, however, can also be used in a more atomic sense to denote only the very final choosing stage of the same process. Of course, this example does not prove that activity verbs are polysemous or semantically ambiguous in general. Otherwise, we also hesitate to make strong claims about the latter, because it is fairly difficult to give a sound empirical basis to any claims about polysemy (see Geeraerts, in press).

\section{Kind-Part Reciprocal Effect}

As we have argued above, the converse part-instance relation is an effect at the level of the ascription of instances to an act category. Hence, it is to be distinguished from Rips and Conrad's (1989) kind-part reciprocal effect, which is situated at the level of the relations between pairs of categories. Yet, the two phenomena seem to be closely related. An indication for this may already be found in the fact that, in common cases of pars pro toto metonymy, kind-part reversals also occur. For example, for strings, one may say that "violins are a kind of strings," but also that "strings are a part of violins." For alcohol, which may be metonymically used to designate any drink containing (ethyl) alcohol, one can say that "beer is a kind of alcohol," but also that "alcohol is part of beer."

More formally, the kind $\rightarrow$ part half of the kind-part reciprocal effect (i.e., the implication "if $V_{2}$ is a kind of $V_{1}$, then $V_{1}$ is part of $V_{2}$ ") can be logically deduced from the converse part-instance relation. To prove this, assume that $V_{2}$ is indeed a kind of $V_{1}$. Consider then an arbitrary instance $v_{2}$ of $V_{2}$. Because of the initial assumption, $v_{2}$ is also an instance of $V_{1}$. But then, because of the converse part-instance relation, some instance of $V_{1}$ is part of $v_{2}$. Hence, since $v_{2}$ was an arbitrary instance of $V_{2}$, $V_{1}$ is part of $V_{2}$.

Moreover, the reverse part $\rightarrow$ kind implication can also be deduced from the converse part-instance relation, though only for important parts (insofar as the converse relation is limited to important parts). Assume that $V_{1}$ is an important part of $V_{2}$. Consider then an arbitrary instance $v_{2}$ of $V_{2}$. Because of the initial assumption, $v_{2}$ has some instance of $V_{1}$ as an important part. But then, by the converse part-instance relation, $v_{2}$ is also an instance of $V_{1}$, and, hence $V_{2}$ is a kind of $V_{1}$.

It must be admitted that the logical link between the converse part-instance relation and the kind-part reciprocal effect does not preclude the psychological validity of other explanations for the kind-part reciprocal effect (Fellbaum \& Miller, 1990; Rips \& Conrad, 1989, 1990). Otherwise, beyond the logical link, it would be interesting to examine empirically whether the occurrence of the converse part-instance relation is associated to the occurrence of its kind-part counterpart.

\section{REFERENCES}

Cruse, D. A. (1986). Lexical semantics. Cambridge: Cambridge University Press.

Fellbaum, C., \& Miller, G. A. (1990). Folk psychology or semantic entailment? A reply to Rips and Conrad. Psychological Review, 97, 565-570.

FrEGE, G. (1964). Begriffsschrift und andere Aufsätze (Zweite Auflage mit E. Husserls und H. Schulz' Anmerkungen, herausgegeben von 1. Angelelli). Hildesheim: Georg Olms. (Original work published 1879) GeeraerTs, D. (in press). Vagueness puzzles, polysemy's vagaries. Cognitive Linguistics.

LAKOFF, G. (1987). Women, fire, and dangerous things. Chicago: University of Chicago Press.

LAKOFF, G., \& JoHnSON, M. (1980). Metaphors we live by. Chicago: University of Chicago Press

RuPs, L. J., Conrad, F. G. (1989). Folk psychology of mental activities. Psychological Review, 96, 187-207.

RIPs, L. J., Conrad, F. G. (1990). Parts of activities: A response to Fellbaum and Miller. Psychological Review, 97, 571-575.

Shrout, P. E., \& FLEISS, J. L. (1979). Intraclass correlations: Uses in assessing rater reliability. Psychological Bulletin, 86, 420-428.

TVersky, B., \& HemenWay, K. (1984). Objects, parts, and categories. Journal of Experimental Psychology: General, 113, 169-191. 


\section{APPENDIX A}

\section{List of Acts Used in Study 1}

This physician follows the abortion law in his own way.

The old woman thinks that the long hair of her grandson is asocial. You suspect someone is friendly for strategic reasons.

You decide to type the text in typeface A rather than in typeface B.

I compare the performance of two different blenders.

I watch the film critically.

I find him behaving towards me like he does towards his father.

You weigh the pros and cons of taking service with $\mathrm{A}$.

I think this woman will make it in life.

In the photographic shop you order matte prints, but you know you can also order glossy prints.

The young couple in the shop finally opts for the Arzberg china, but they also found the Hutschenreuter very nice.

The racist suspects the behavior of the Turks.

In the multiple choice exam "Psychological Assessment Methods" you select the second alternative for item 3 .

The man who arrives with his car at a safety island where a double white arrow on a blue ground indicates that that island can be passed on the left or on the right, passes it on the right because the trolley rails on the left are more dangerous.

You wonder whether you would purchase a diesel or a gas engine.

I take the green instead of the red apple.

The child herself composes the menu for her birthday.

You examine thoroughly the learning problem of a child.

The tourists determine which way they will take after the guide has mapped out two alternative routes.

The jury considers this manslaughter to be legitimate self-defense.

The student determines which out of two lectures scheduled at the same hour he will attend.

The restaurant cook considers which vegetables he will buy at the early morning market.

The chemist studies the surface water of the small Dyle river.

The technician takes apart the television in search of a failure.

I look for the themes that occur in a text.

Scientists study the most recent jumping technique of our high-jumpers.

The chess player considers what will be the most probable move of his opponent.

F. De Winter (of the Flemish Block Party) views the slogan "Flanders free" in a different, more extreme way.

I believe he tells the truth.

To her his silence was a sign of his repudiation.

The secretary divides the report of the last meeting of the department council into headings.

The paranoid man sees a spy in every passerby.

The woman first examines the issue quietly before determining her behavior.

You consider whether you will move or not at a given moment.

I will still go to the 24-hour race of Ieper.

The preschooler knows which candy to take first.

You suspect somebody with a red nose is regularly on the bottle.

You have debated for a long time between "Joe" and "John," but finally you call your newborn "John."

I determine the composition of this chemical product.

The BBC reporter gives his own opinion of Mitterand's speech on the German reunification.

You examine what are the possible consequences of informing your Head of your blunder.

The priest assigns more meaning to Christ's crucifixion than we can guess.

The psychoanalytic psychotherapist explains the candle in the hysteric patient's dream as a phallic symbol.

With an engine problem during the holidays you examine the situation thoroughly in order to be helped well and cheaply.

\section{APPENDIX B}

List of Acts Used in Study 2

I thought that the more paper I used, the more trees would go. His eyes filled with tears when he heard "no pass" after his name.
After the semester's exams he saw that he had to study quite differently. The suspicious man thought again that they all had it in for him.

When I woke up on that summery day, I was so happy that I found everything and everybody fantastic.

The university student thought he was better than all other people.

Mark thought about his future: in a convertible with the wind in his hair.

When he saw the bright sun in the sky he was so happy

"This would be tasty with cheese and ham," he thought when he ate the dry slice of bread.

When everything was somewhat against him he was incredibly depressed.

When I had met that unknown girl yesterday on the street, I fantasized that she would come and see me that evening.

After that pleasant day I blissfully sat on the couch at night.

You thought that if you had run a little bit faster, you would not have missed the train.

When Mom told us a tale of the old days, I thought up the pictures with it.

When my mother became sick, I became aware of how important it is to be healthy.

I was in a cold sweat when the elevator got stuck.

After the mocking remark, he understood too well that it was aimed at him.

When he saw that he still had a lot of work, he thought it would be better not to go on vacation.

Much ran through my mind when the train in which I sat knocked down a pedestrian who stood on the railway tracks.

After he had got his diploma, he observed that it does not offer a guarantee for a job.

After his severe accident he suddenly took a relative view of everything. I think that in a few years my working situation will look quite different

When the teacher started to become angry, John knew that it would be better to leave the classroom.

I was terribly scared when upon my return home I found there had been a burglary.

When the opposing team had made its third goal the coach knew that the chance for qualification was gone.

John was angry when Jack got a ball from his parents whereas he did not get one.

It was not until he arrived home after the funeral that he burst into tears. After he had knocked down a child he saw that it was stupid to drive under the influence.

John thinks he swims better than Pete, but the reverse is actually true. When he knew he had done well on the exam, he shouted for joy.

I lay back on my bed when Raymond Van het Groenewoud's "Being Happy" came from the loudspeakers: wonderful.

He thought he had been hit, although the bandit had not shot except with dummy cartridges.

When I had opened the envelope, and saw that it came from her, it got me hot.

"How would it be now in the Bahamas?" he wondered when he turned the next page of his textbook.

When he saw in a flash the bike crashing into the car he thought that the bike had jumped the lights (which was not the case).

I was touched upon seeing the Monet painting.

He fantasized that his love, who was traveling with her parents, came and sat down next to him.

At the talent scouting, mother thought her little son could become very famous.

When the prof asked, "Did you have re-examinations last year as well?" he was on to the fact that he could forget about his vacations

After the horror film, she heard things that were not there.

It was not until my grandfather died that I found the hold he had had over my life.

George looked into his girlfriend's eyes with an expression of "I love you."

When Mary had fallen, she wept in pain.

"In my caravan I am Superman," he thought.

\section{APPENDIX C List of Acts Used in Study 3}

While he gathers all his forces, the discus thrower tries to make the discus land as far as possible from him. 
He tightened the screw.

He knocked the vase off the table.

He put the crown cork back on the bottle.

He moved a large stone by hand.

He made the ball fly to the basket with an elegant move.

In the disco, he danced with his girlfriend during a hard rock song

He slung a towel at her.

He put the lid on the jam jar.

In the heat of the discussion, the man squeezed his wife and pinned her against the wall.

When the exasperating Ann disturbs the intimate conversation between Heidi and her friend, Heidi whips around rudely.

He flung a stone at the cat's head.

He cranked up the old-timer to make it start.

He chucked the bit of paper into the wastebasket.

The cyclist went three times around the village square.

During the football match, one player tries to impede another one getting to the ball while they are running towards it side by side.

When I had noticed that I was driving in the wrong direction, I went back with my bike.

He made the meat broil on the other side on the spit.

The model showed herself from all angles at the fashion show.

In the swimming pool, he held his friend's head under water.

He made the dial move with his finger in order to call.
While playing, two youngsters sling their friend into the sea When he saw the prof arriving, he whipped around.

When he was angry, he made the books fly against the wall. He pressed the bell.

The little children made the pebbles land in the water.

The dancer swirled graciously around her partner.

He edged his way through the crowd.

The driver made his car take the bend.

The circus performer catapults himself away during his act.

The squatter forcefully dropped a stone from the house onto the street.

To make his name somewhat better known in the city, the businessman scattered advertising brochures.

The old farmer ploughed his field on his own.

The mother labored hard to give birth to her baby.

He was reeling with joy.

Pete flung the hammer very far away.

When the car broke down, daughter and mother tried to make it move forward forcefully in order to get it going again.

The ballerina spun around.

George thrusts the cart ahead.

The preschooler spun around with his arms.

(Manuscript received November 27, 1990; revision accepted for publication May 29, 1992.) 